\title{
Clinical features of 11 patients with opsoclonus-myoclonus syndrome diagnosed in an urban pediatric institution in Mexico City: A retrospective study
}

\author{
Alejandra Castañón-González¹, Eduardo Barragán-Pérez², Eduardo González-Negrete³, \\ Arturo Llanes-Ojeda ${ }^{4}$, Fiacro Jiménez-Ponce ${ }^{5,6,7,8}$ and Julio César López-Valdés ${ }^{4,6 *}$
}

${ }^{1}$ Department of Neurology, Unidad Médica de Alta Especialidad, Hospital de Pediatría "Dr. Silvestre Frenk Freund", Centro Médico Nacional Siglo XXI, Instituto Mexicano del Seguro Social (I.M.S.S.), Mexico City; ${ }^{2}$ Department of Neurology, "Hospital Infantil de México Federico Gómez," Mexico City, Mexico; ${ }^{3}$ Department of Postgraduate, Universidad Nacional Autónoma de México, Mexico City; ${ }^{4}$ Department of Research, Universidad Autónoma de Tamaulipas, Facultad de Medicina de Tampico "Dr. Alberto Romo Caballero," Tampico, Tamaulipas; ${ }^{5}$ Service of Neurology and Neurosurgery, Hospital General de México "Dr. Eduardo Liceaga," Mexico City; ' ${ }^{6}$ Department of Research, Hospital Ángeles de Pedregal, Mexico City; ${ }^{7}$ Department of Medical Research, Cognitive Science, S.A., Mexico City; ${ }^{8}$ Department of Teaching and Medical Investigation, Instituto de Seguridad y Servicios Sociales de los Trabajadores del Estado, Mexico City. Mexico

\begin{abstract}
Background: Opsoclonus-myoclonus syndrome (OMS) is an immune-mediated disorder that affects the central nervous system. It is recognized as a paraneoplastic syndrome highly associated with neuroblastic tumors. In Mexico, accurate epidemiological data are lacking and there are no well-structured protocols aimed at standardizing a treatment regimen in patients with OMS. Aim: This study aims to describe the clinical features, etiological factors, and treatment related to OMS in Mexican children. Patients and Methods: A retrospective study was performed over a 10-year period (2006-2016), using the database of the "Hospital Infantil de México Federico Gómez". The patients were divided into two groups (tumor vs. no tumor) to determine if there were significant demographic differences between the subgroups. The demographic variables were compared between groups using the Student's t-test. Results: Eleven patients were identified. The median age at the onset of the first clinical manifestation was $23 \pm 14$ months and the median age at diagnosis was $26 \pm 15$ months. The time delay between the onset of symptoms and diagnosis was approximately 3 months. Conclusion: In Mexico, there is a paucity of experience regarding the clinical presentation of OMS, and due to the infrequency of this condition, it is rarely diagnosed in our population since most pediatricians are unaware of the existence of the syndrome. The findings of this paper are consistent with the previous studies in terms of a closely equal sex ratio, predominance of Stage I tumors, a greater number of female patients with a paraneoplastic etiology, high relapse rates, and frequent neuropsychiatric morbidity.
\end{abstract}

Key words: Kinsbourne syndrome. Opsoclonus-myoclonus syndrome. Ataxia. Neuroblastoma.

\section{Correspondence:}

*Julio César López-Valdés

E-mail: jc.lopz@live.com
Available online: 09-08-2019

Date of reception: 30-01-2019

Date of acceptance: 07-05-2019 DOI: 10.24875/RMU. 19000055
Medicina Universitaria. 2019;21(2):82-88 www.medicinauniversitaria.org

(the CC BY-NC-ND license (http://creativecommons.org/licenses/by-nc-nd/4.0/). 


\section{Introduction}

Opsoclonus-myoclonus-ataxia syndrome (OMS), also known as "Kinsbourne syndrome," is an immune-mediated disorder that affects the central nervous system; it is characterized by involuntary chaotic saccades (random and multidirectional eye movements) and is usually accompanied by tremors, ataxia (imbalance, incoordination), and myoclonic spasms that affect the whole body, along with extreme irritability and behavioral changes ${ }^{1-5}$.

The estimated incidence in children is $0.27-0.40$ cases per million ${ }^{5}$. The average age of the onset of pediatric OMS is 18 months $^{6}$. It is recognized as a paraneoplastic syndrome highly associated with neuroblastic tumors (neuroblastoma [NB], ganglioneuroblastoma, or ganglioneuroma) and more rarely with other tumors $(50 \% \text { of cases })^{2,5,7,8}$. Furthermore, OMS may be parainfectious (infective or post-infective) or idiopathic ${ }^{7-9}$.

Female patients tend to present tumoral OMS more frequently than males ${ }^{10}$. Non-tumoral cases tend to be triggered by a variety of infections caused by viruses (e.g., rotavirus, enterovirus, dengue, Chikungunya, mumps, varicella, HIV, and many others), bacteria (e.g., Mycoplasma spp.), and parasites (e.g., Plasmodium falciparum) ${ }^{9-11}$. In addition, there are some cases that have been related to immunizations (e.g., human papillomavirus) ${ }^{11}$. The clinical presentation of OMS is identical in all patients regardless of the underlying etiology. In some cases, opsoclonus may present as a late clinical feature, in which case OMS may be misdiagnosed in the early course of the disease as acute cerebellar ataxia, since the presence of opsoclonus is needed to exclude the diagnosis of the latter ${ }^{10}$.

The hallmark of this syndrome is the constant risk of recurrence and relapse of neurological symptoms after the immunosuppressive treatment is decreased ${ }^{12}$. Moreover, the neurological and neuropsychiatric effects of OMS are devastating and permanent (e.g., attention-deficit disorder, learning and memory disorders, and cognitive impairment) $5,11,13$. In $70-80 \%$ of cases, it results in lifelong neurological disability ${ }^{12}$.

In Mexico, there is a lack of accurate epidemiological data and there are no well-structured protocols aimed at standardizing a treatment regimen in patients with OMS. In this study, we reviewed patient medical records at the Hospital Infantil de México Federico Gómez to analyze the clinical and demographic features of Mexican children diagnosed with OMS. We also sought to determine how timely and accurate the diagnosis and the initiation of treatment were in our population. The authors present a useful algorithm outlining the diagnostic approach and treatment protocols in these cases.

\section{Patients and methods}

We retrospectively assessed pediatric patients who were treated for OMS with or without an NB from January 2006 to December 2016 at the Division of Neurology of a single, large tertiary pediatric institution in Mexico City. Eligible patients were those who had a diagnosis of OMS defined by the presence of at least three of the following criteria: opsoclonus, ataxia/myoclonus, behavioral changes, and NB. The medical records of these patients admitted for OMS were reviewed. Demographic data (e.g., sex, age, age at diagnosis, first clinical manifestation, etiological cause, evaluation criteria for OMS, and relapse of the neurological symptoms), histopathology (if available), and treatment were retrospectively reviewed from the records. The severity of the neurological symptoms was assessed by the OMS evaluation criteria ${ }^{14}$.

For this study, a relapse was defined as the abrupt and discernible reemergence of OMS symptoms and signs in a child who was previously in remission, which was only achieved after an intensive and sustained intervention ${ }^{6}$.

The data were analyzed using Microsoft Office $2016^{\text {TM }}$. The results are shown in the form of simple frequencies, means, standard deviation, and percentages.

The patients were divided into two groups: the first group included patients with an identified NB (referred to as the tumor group) and the second group included patients with no identified NB (no tumor group). The objective of this study was to determine whether or not significant demographic differences between the two etiological subgroups existed. The variables were compared between both groups using the Student's t-test; $p<0.05$ was considered statistically significant.

This study was carried out in accordance with the ethical recommendations of the responsible human experimentation committee and in agreement with the World Medical Association and the Declaration of Helsinki.

\section{Results}

Eleven patients (six females and five males) diagnosed with OMS were identified. The median age at onset of the first clinical manifestation was $23 \pm 14$ months (range: 9-52 months) and the median age at diagnosis was $26 \pm 15$ months (range: 11-54 months). The time delay from the onset of symptoms to the diagnosis was approximately 3 months. The follow-up period ranged from 0 months to 84 months (median 32.36 months) and 
Table 1. Demographic analysis

\begin{tabular}{|c|c|c|c|c|c|c|c|c|}
\hline ID & Sex & $\begin{array}{l}\text { Age of } \\
\text { symptoms } \\
\text { onset* }\end{array}$ & $\begin{array}{c}\text { Age of } \\
\text { diagnosis* }\end{array}$ & $\begin{array}{c}\text { Age of } \\
\text { treatment }\end{array}$ & $\begin{array}{l}\text { Onset clinical } \\
\text { manifestation }\end{array}$ & Etiology & Neuroblastoma & $\begin{array}{c}\text { OMS } \\
\text { evaluation } \\
\text { criteria }\end{array}$ \\
\hline 1 & $\mathrm{~F}$ & 9 & 11 & 12 & $A, 0$ & Paraneoplastic & Paravertebral & 13 \\
\hline 2 & M & 17 & 21 & 22 & $A, 0$ & Post-infectious & No & 11 \\
\hline 3 & $\mathrm{~F}$ & 17 & 18 & 19 & $A, 0, M, B C$ & Paraneoplastic & Adrenal & 12 \\
\hline 4 & M & 52 & 54 & 54 & $A, 0, B C$ & Idiopathic & No & 8 \\
\hline 5 & $\mathrm{~F}$ & 51 & 53 & 53 & $B C$ & Paraneoplastic & Paravertebral & 10 \\
\hline 6 & M & 33 & 34 & 34 & $A, M$ & Post-infectious & No & 14 \\
\hline 7 & M & 14 & 25 & 25 & $A, 0$ & Post-infectious & No & 12 \\
\hline 8 & $\mathrm{~F}$ & 15 & 15 & 16 & $\mathrm{~A}, 0, \mathrm{M}$ & Paraneoplastic & Adrenal & 15 \\
\hline 9 & $\mathrm{~F}$ & 14 & 15 & 15 & 0 & Post-infectious & No & 12 \\
\hline 10 & M & 14 & 18 & 18 & A & Idiopathic & No & 14 \\
\hline 11 & $\mathrm{~F}$ & 21 & 22 & 22 & A & Paraneoplastic & Paravertebral & 15 \\
\hline Total & $\begin{array}{l}\text { Male 5/ } \\
\text { Female } \\
6\end{array}$ & $\begin{array}{c}\mu=23 \pm 14 \\
\text { (SD) } \\
\text { months }\end{array}$ & $\begin{array}{c}\mu=26 \pm 15 \\
\text { (SD) } \\
\text { months }\end{array}$ & $\begin{array}{c}\mu=27 \pm 15 \\
\text { (SD) } \\
\text { months }\end{array}$ & $\begin{array}{l}\text { Ataxia } 9 / \text { opsoclonus } \\
6 / \text { myoclonus } 3 / \\
\text { behavioral changes } \\
3\end{array}$ & $\begin{array}{l}\text { Paraneoplastic } \\
5 / \\
\text { post-infectious } \\
\text { 4/idiopathic } 2\end{array}$ & $\begin{array}{l}\text { Tumor } 5 / \text { No } \\
\text { tumor } 6\end{array}$ & $\begin{array}{l}12.36 \pm 2.15 \\
\text { (SD) points }\end{array}$ \\
\hline
\end{tabular}

The table displays the following information: sex (M or $\mathrm{F}$ ), age of onset, age of diagnosis, age of treatment, onset manifestation $(\mathrm{A}, \mathrm{O}, \mathrm{M}$ and $\mathrm{BC})$, etiological cause, presence or absence of neuroblastoma, and OMS evaluation criteria.

M: male; F: female, A: ataxia; 0: opsoclonus; M: myoclonus; BC: behavioral changes; OMS: opsoclonus-myoclonus syndrome.

the relapse rate was $1.27 \pm 0.9$ times. Demographic findings are shown in Table 1.

In all cases, the predominant manifestation was ataxia followed by other clinical signs of OMS, which appeared secondarily. All patients in this series were initially misdiagnosed with acute cerebellar ataxia.

When the patients were assessed using OMS evaluation criteria, we obtained a mean of $12.3 \pm 2.4$ (range: 7-15) points (Table 2).

All children were screened for a primary NB, but the detection methods were heterogeneous due to the large recruitment period and the evolution of clinical practice.

All patients received steroids as the first line of treatment, with the exception of two who received therapy for symptoms of epilepsy. Six children received intravenous immunoglobulins (IVIG), just after surgical resection of the tumor, and in almost all cases, an antiepileptic drug was prescribed. The number of steroid pulses was decided based on the clinical response observed, the patient's compliance to the treatment, and the child neurologist's personal experience. For symptomatic treatment of myoclonus, clonazepam was the preferred drug.

Two children (cases 4 and 5) presented a late onset of symptoms and were evaluated until age 4 . One of these patients was later diagnosed with an NB.
Spontaneous improvement of symptoms occurred in one case; it is noteworthy to mention that the information about the follow-up in the clinical file is not clear (case 4). Fourteen relapses were noted in 11 patients (Table 3).

\section{Oncological data}

In five patients, an OMS associated with NB was observed, all of them in Stage I, according to the International NB Staging System Committee ${ }^{15}$. The most common anatomical localization of the NB in this series was the paravertebral area (three cases). The presence of tumors was more frequent in the female patients $(p=0.0014)$.

Their median age at diagnosis was $22.6 \pm 16.46$ months (range: from 9 to 51 months). The relapse rate was $1.6 \pm 0.55$ for this group. In three cases, the oncological treatment consisted of chemotherapy (cyclophosphamide) plus surgery. Immunosuppressive therapy (steroids and IVIG) was administrated in all patients.

Comparing both groups (tumor group/no tumor group), there was no significant difference in age at onset of symptoms, first clinical manifestation or the median of points obtained by the OMS evaluation criteria. Results are shown in Table 4. 
Table 2. Clinical evaluation criteria, (Genoa consensus, 2004), for Kinsbourne syndrome diagnosis

\begin{tabular}{|c|c|c|c|c|c|c|}
\hline ID & Opsoclonus & Myoclonus & Gait & Stance & Behavioral/Mood & Total \\
\hline 1 & 3 & 2 & 3 & 12 & $A, 0$ & Paraneoplastic \\
\hline 2 & 2 & 2 & 3 & 22 & $A, 0$ & Post-infectious \\
\hline 3 & 2 & 2 & 3 & 19 & $\mathrm{~A}, 0, \mathrm{M}, \mathrm{BC}$ & Paraneoplastic \\
\hline 4 & 2 & 1 & 2 & 54 & $A, 0, B C$ & Idiopathic \\
\hline 5 & 2 & 1 & 3 & 53 & $\mathrm{BC}$ & Paraneoplastic \\
\hline 6 & 4 & 2 & 3 & 34 & $A, M$ & Post-infectious \\
\hline 7 & 3 & 2 & 3 & 25 & $A, 0$ & Post-infectious \\
\hline 8 & 3 & 3 & 3 & 16 & $A, 0, M$ & Paraneoplastic \\
\hline 9 & 2 & 2 & 3 & 15 & 0 & Post-infectious \\
\hline 10 & 3 & 2 & 3 & 18 & A & Idiopathic \\
\hline 11 & 3 & 3 & 3 & 22 & A & Paraneoplastic \\
\hline $\begin{array}{l}\text { Total } \\
\text { points }\end{array}$ & $\begin{array}{l}\mu=2.64 \pm 0.67 \\
(S D) \text { points }\end{array}$ & $\begin{array}{l}\mu=2 \pm 0.63 \\
\text { (SD) points }\end{array}$ & $\begin{array}{l}\mu=2 \pm 0.63 \\
\text { (SD) points }\end{array}$ & $\begin{aligned} \mu= & 27 \pm 15(S D) \\
& \text { months }\end{aligned}$ & $\begin{array}{l}\text { Ataxia 9/opsoclonus 6/ } \\
\text { myoclonus 3/behavioral } \\
\text { changes } 3\end{array}$ & $\begin{array}{l}\text { Paraneoplastic 5/ } \\
\text { post-infectious 4/idiopathic }\end{array}$ \\
\hline
\end{tabular}

Table 3. Clinical characteristics comparing both groups: "tumor" versus " no tumor"

\begin{tabular}{|l|c|c|c|}
\hline Variable & Tumor (n = 5) & No tumor (n= 6) & $\mathbf{p}$ value \\
\hline Sex (Male: female) & $0: 5$ & $5: 1$ & 0.0014 \\
\hline Age* & $22.6 \pm 16.46$ (SD) & $24 \pm 15.58$ (SD) & 0.8881 \\
\hline Onset symptom (s)* & Acute ataxia & Acute ataxia & $-\cdots$ \\
\hline Range between onset of symptom (s) to diagnosis* & $1.2 \pm 0.84$ (SD) & $3.83 \pm 3.76$ (SD) & 0.08 \\
\hline Range between diagnosis to treatment* & $0.6 \pm 0.55$ (SD) & $0.33 \pm 0.52$ (SD) & 0.074 \\
\hline OMS scale before diagnosis & $13 \pm 2.12$ (SD) & $11.67 \pm 2.58$ (SD) & 0.3806 \\
\hline Opsoclonus severity before the diagnosis & $2.6 \pm 0.55$ (SD) & $2.67 \pm 0.82$ (SD) & 0.8801 \\
\hline Myoclonus severity before the diagnosis & $2.2 \pm 0.84$ (SD) & $1.83 \pm 0.41$ (SD) & 0.3655 \\
\hline Ataxia (on walk) before the diagnosis & $3 \pm 0$ (SD) & $2.83 \pm 0.41$ (SD) & 0.3893 \\
\hline Ataxia (postural) before the diagnosis & $3 \pm 0$ (SD) & $2.5 \pm 0.84$ (SD) & 0.2181 \\
\hline Behavioral changes severity & $2.20 \pm 0.84$ (SD) & $2.17 \pm 0.75$ (SD) & 0.9460 \\
\hline Relapses & $1.6 \pm 0.55$ (SD) & $1 \pm 1.09$ (SD) & 0.1483 \\
\hline
\end{tabular}

\section{Discussion}

In this study, the clinical features of 11 Mexican patients diagnosed with OMS during 11 years were analyzed based on the medical records of the Hospital Infantil de México Federico Gómez, thus representing the OMS case series with the longest time frame reported in Mexico to date. Similar to many other countries, this study underscores the paucity of experience regarding the clinical presentation of OMS, and due to the infrequency of this condition, it is rarely diagnosed in our population since most pediatricians are unaware of the existence of the syndrome.

The findings of this paper are consistent with the previous studies in terms of a closely equal sex ratio, predominance of Stage I tumors, a greater number of 
Table 4. Therapeutic demographic characteristics

\begin{tabular}{|c|c|c|c|c|c|}
\hline ID & Initial Treatment & Pharmacological treatment & Frequency & Follow-up (months) & Relapses \\
\hline 1 & $S X+P M$ & $S+I V I g+C P+(C L Z$ daily) & Monthly $\times 6$ & 12 & 1 \\
\hline 2 & PM & $S+I V I g+C P+(C L Z$ daily) & Monthly $\times 6$ & 47 & 1 \\
\hline 3 & $S X+P M$ & $S+I V I g+(C L Z$ daily) & Monthly $\times 6$ & 16 & 2 \\
\hline 4 & PM & $C L Z+A E D$ & At diagnosis & 0 & 1 \\
\hline 5 & $S X+P M$ & $S+I V I g+A E D$ & Irregular* & 48 & 2 \\
\hline 6 & PM & $S+C L Z+A E D$ & At diagnosis & 6 & 0 \\
\hline 7 & PM & $S+A E D$ & At diagnosis & 6 & 1 \\
\hline 8 & $S X+P M$ & $S+I V I g+C P+C L Z$ & Irregular* & 60 & 1 \\
\hline 9 & PM & Other & At diagnosis & 84 & 0 \\
\hline 10 & PM & $S+C P$ & At diagnosis & 48 & 3 \\
\hline 11 & $S X+P M$ & $S+I V I g+C P+(C L Z$ daily) & Monthly $\times 6$ & 29 & 2 \\
\hline Total & PM 6/SX + PM 5 & $\begin{array}{l}\mathrm{S}+\mathrm{IVIg}+\mathrm{CP}(+\mathrm{CLZ}) \\
3 / \mathrm{S}+\mathrm{IVIg}+\mathrm{CLZ} 1 / \mathrm{CLZ}+\mathrm{AED} \\
1 / \mathrm{S}+\mathrm{IVIg}+\mathrm{AED} 1 / \mathrm{S}+\mathrm{CLZ}+\mathrm{AED} \\
1 / \mathrm{S}+\mathrm{AED} 1 / \mathrm{S}+\mathrm{IVIg}+\mathrm{CP}+\mathrm{CLZ} \\
1 / \mathrm{S}+\mathrm{CP} 1 / 0 \text { ther } 1\end{array}$ & $\begin{array}{l}\text { At diagnosis 5/monthly } \\
4 / \text { irregular } 2\end{array}$ & $\mu=32.36 \pm 26.95$ (SD) & $\mu=1.27 \pm 0.9$ (SD) \\
\hline
\end{tabular}

SX: surgery. PM: pharmacology. S: steroids, IVIg: immune globulin IV, CP: cyclophosphamide; LZ: clonazepam, AED: antiepileptic drug.

*The relatives did not have a correct attachment to the treatment, they administered the medications when they observed behavior changes

female patients with a paraneoplastic etiology, high relapse rates, and frequent neuropsychiatric morbidity.

Similar to the findings reported by Castellanos-Toledo et al. ${ }^{16}$ (23.1 months, range: 11-47 months), we observed a higher median age at clinical presentation (22.6 months, range: 9-51 months) in Mexican children. Moreover, the average duration of therapy was nearly equal in both studies (33 vs. $32.36 \pm 26.95$ months), but there was a lower median time in symptom duration (4.3 months vs. $2.45 \pm$ 1.9 months). When comparing clinical features between the etiological subgroups in our study with the information reported by Castellano-Toledo et al. ${ }^{16}$, we found that they reported no gender differences in the incidence of NB, while our study showed a clear predominance of females in the tumor group. Furthermore, the primary localization of NB was the adrenal gland (five cases), while there was only one case localized in the paravertebral area (mediastinum). Finally, they mentioned two cases in intermediate and high-risk stages with no relapses or progression for the disease. One possible explanation for some of the differences found when comparing these two studies could be the different therapeutic regimens used (IVIG, prednisone, and methotrexate).

The ideal treatment for OMS has not been standardized and is based mainly on the experience and expertise obtained when treating individual cases. For this reason, different treatment modalities, including steroids, cyclophosphamide, IVIG, methotrexate, 6-mercaptopurine, azathioprine, rituximab, mycophenolate, and plasmapheresis, have been proposed with variable efficacy and many side effects ${ }^{17-21}$. Nevertheless, in contrast with the information reported by studies in other countries, the use of a therapeutic protocol based on ACTH or rituximab is limited in Mexico. However, cyclophosphamide and dexamethasone are widely available in tertiary hospitals, and both drugs have demonstrated satisfactory results as immunosuppressive options ${ }^{19}$.

In our study, we observed a good therapeutic response with a treatment protocol for OMS that included as follows: cyclophosphamide I.V. at $150 \mathrm{mg} / \mathrm{m}^{2} / \mathrm{day}$, for 7 days, monthly for 6 consecutive months ( 6 cycles). IVIG I.V. at $2 \mathrm{~g} / \mathrm{kg}$ monthly for 6 consecutive months ( 6 cycles) and dexamethasone administered I.V. at a dose of $20 \mathrm{mg} / \mathrm{m}^{2} /$ day, for 3 days, monthly for 6 consecutive months $(6 \text { cycles })^{2}$. This is the treatment protocol that we propose based on the information obtained from international literature, as well as the satisfactory response observed in our patients with OMS (cases 1,2, and 11).

This study can be regarded as an attempt to establish an appropriate and standardized treatment protocol for patients with OMS in Mexico, since it takes into account the numerous limitations, in terms of the low availability of treatment options that many Mexican pediatricians face when treating these patients. Based on the good clinical 


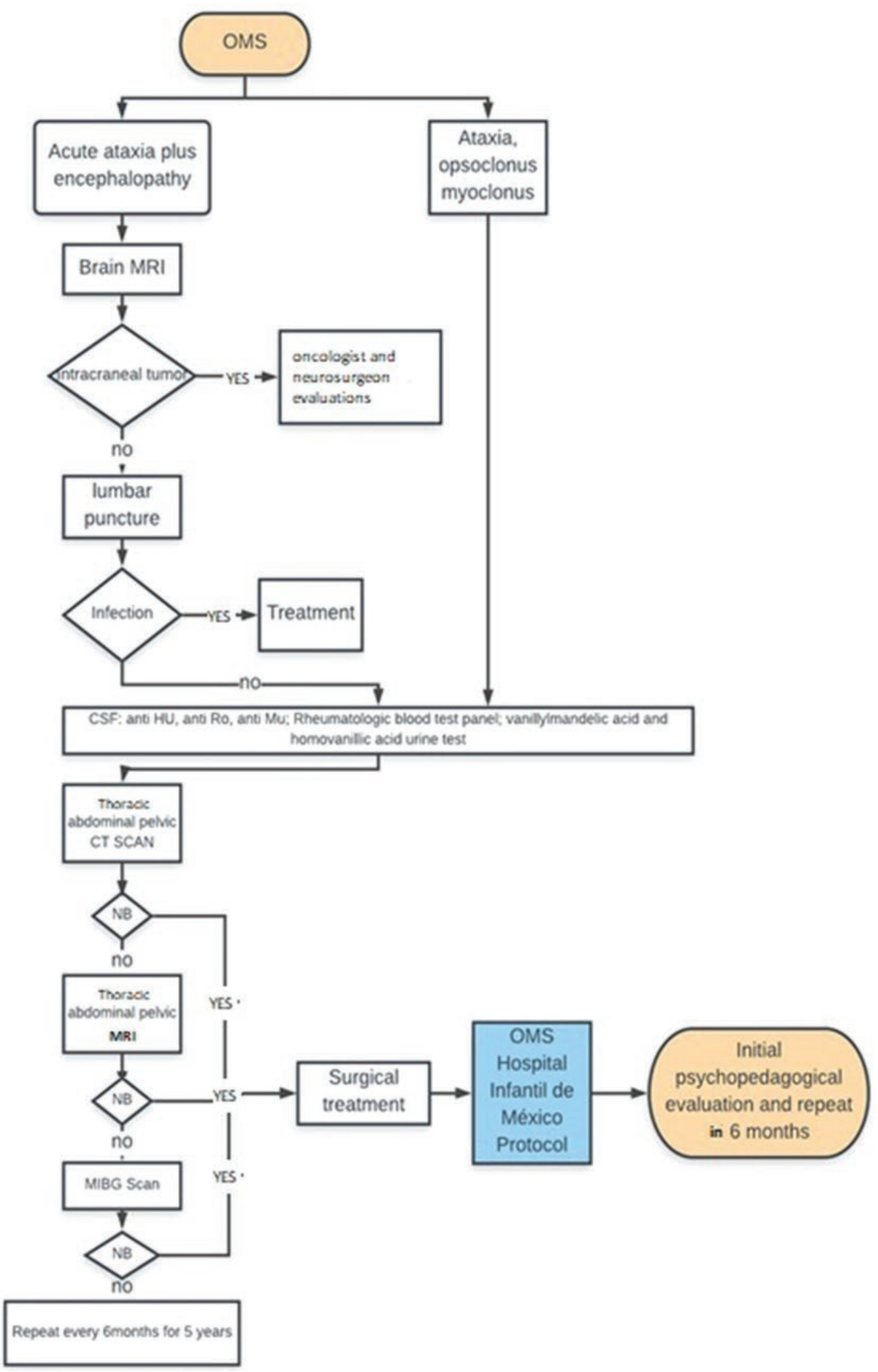

Figure 1. Algorithm to diagnose the opsoclonus-myoclonus syndrome in children at Hospital Infantil de México Federico Gómez. 
response observed in our patients, we believe that this alternative treatment protocol will improve the prognosis of many children with this syndrome in Mexico.

The complete diagnosis algorithm is described in Fig. 1.

\section{Limitations}

The results should be interpreted with caution due to the retrospective nature and small sample size of this study. Furthermore, we were not able to explore the association between the immune mechanism proposed and the long-term neurological consequences. All children were screened for a primary NB, but the detection methods were heterogeneous due to the large recruitment period and the evolution of clinical practice. Therefore, the implementation of a large population-based survey is needed to provide more accurate information about opsoclonus-myoclonus syndrome.

\section{Conclusion}

It is possible to observe that, like most of the literature, the information is not yet possible to make a diagnostic of certainty in the parents and the women of the Kinsbourne syndrome soon, reason why it is a delay in the beginning of the measures to limit the psychomotor damage that these patients suffer. But on the other hand, a difference of the literature, this study showed a greater predominance in the female sex in comparison with existing medical literature. Likewise, a large number of similarities and descriptions ethnic groups were fund. It is considered necessary to educate pediatricians about the existence of said syndrome, this in order to reduce the time of diagnosis.

\section{Conflicts of interest}

No conflicts of interest were declared by the authors.

\section{Funding}

This research received a grant from "Beca Impulso a la Investigación, 2016" awarded to Alejandra Castañón González to support her medical specialization by "Fundación Carlos Slim, A.C."

\section{Ethical disclosures}

Protection of human and animal subjects. The authors declare that the procedures followed were in accordance with the regulations of the relevant clinical research ethics committee and with those of the Code of Ethics of the World Medical Association (Declaration of Helsinki).

Confidentiality of data. The authors declare that they have followed the protocols of their work center on the publication of patient data.

Right to privacy and informed consent. The authors have obtained the written informed consent of the patients or subjects mentioned in the article. The corresponding author is in possession of this document.

\section{References}

1. Ben Achour N, Mrabet S, Rebai I, Abid I, Benrhouma $\mathrm{H}$, Klaa H, et al. Childhood opsoclonus-myoclonus syndrome: a case series from Tunisia. Brain Dev. 2017;39:751-5.

2. Castañón-González A, Barragán-Pérez E, Hernández-Pliego G, López-Valdés JC. Terapia inmunosupresora en síndrome de opsoclonus-mioclonus ataxia asociado a un neuroblastoma paravertebral. Neurología. 2017. Disponible en https://www.elsevier.es/es-revista-neurologia-295-pdf-S0213485317302554.

3. Meena JP, Seth R, Chakrabarty B, Gulati S, Agrawala S, Naranje P, et al. Neuroblastoma presenting as opsoclonus-myoclonus: a series of six cases and review of literature. J Pediatr Neurosci. 2016;11:373-7.

4. Gallerini S, Marsili L. Pediatric opsoclonus-myoclonus syndrome: the role of functional brain connectivity studies. Dev Med Child Neurol. 2017;59:14-5.

5. Pranzatelli MR, Tate ED, McGee NR. Demographic, clinical, and immunologic features of 389 children with opsoclonus-myoclonus syndrome: a cross-sectional study. Front Neurol. 2017;8:468.

6. Pranzatelli MR, Tate ED. Trends and tenets in relapsing and progressive opsoclonus-myoclonus syndrome. Brain Dev. 2016;38:439-48.

7. Galstyan A, Wilbur C, Selby K, Hukin J. Opsoclonus-myoclonus syndrome: a new era of improved prognosis? Pediatr Neurol. 2017;72:65-9.

8. Hasegawa S, Matsushige T, Kajimoto M, Inoue H, Momonaka H, Oka M, et al. A nationwide survey of opsoclonus-myoclonus syndrome in Japanese children. Brain Dev. 2015;37:656-60.

9. Garg RK, Rizvi I, Malhotra HS, Kumar N. Opsoclonus myoclonus syndrome in children: paraneoplastic versus parainfectious. Neurol India. 2018:66:1295-8.

10. Khadilkar S, Benny R. Opsoclonus myoclonus ataxia syndrome. Neurol India. 2018;66:1293-4.

11. Huddar A, Bindu PS, Nagappa M, Bharath RD, Sinha S, Mathuranath PS, et al. Pediatric opsoclonus-myoclonus-ataxia syndrome: experience from a tertiary care university hospital. Neurol India. 2018;66:1332-7.

12. Krug P, Schleiermacher G, Michon J, Valteau-Couanet D, Brisse H, Peuchmaur M, et al. Opsoclonus-myoclonus in children associated or not with neuroblastoma. Eur J Paediatr Neurol. 2010;14:400-9.

13. Prabhu SP. Neuroimaging in pediatric opsoclonus-myoclonus syndrome: beyond the search for neuroblastomas. Dev Med Child Neurol. 2015;57:212-3.

14. Matthay KK, Blaes F, Hero B, Plantaz D, De Alarcon P, Mitchell WG, et al. Opsoclonus myoclonus syndrome in neuroblastoma a report from a workshop on the dancing eyes syndrome at the advances in neuroblastoma meeting in Genoa, Italy, 2004. Cancer Lett. 2005;228:275-82.

15. Kaneko M. Introduction of the international neuroblastoma staging system (INSS). J Jpn Soc Pediatr Surg. 1997;33:249-55.

16. Castellanos-Toledo A, Portillo-Zavala CS, Cardenas-Cardos R, Figueroa-Carbajal JJ. Clinical features and long-term sequelae among children with neuroblastoma and opsoclonus-myoclonus syndrome at diagnosis: experience of the Instituto Nacional de Pediatria, Mexico City, Mexico. $\mathrm{J}$ Clin Oncol. 2018;36:e22509.

17. Thakkar K, Maricich SM, Alper G. Acute ataxia in childhood: 11-year experience at a major pediatric neurology referral center. J Child Neurol. 2016;31:1156-60.

18. Veneselli E, Conte M, Biancheri R, Acquaviva A, De Bernardi B. Effect of steroid and high-dose immunoglobulin therapy on opsoclonus-myoclonus syndrome occurring in neuroblastoma. Med Pediatr Oncol. 1998;30:15-7.

19. Wilken B, Baumann M, Bien CG, Hero B, Rostasy K, Hanefeld F, et al Chronic relapsing opsoclonus-myoclonus syndrome: combination of cyclophosphamide and dexamethasone pulses. Eur J Paediatr Neurol. 2008;12:51-5.

20. Pranzatelli MR, Tate ED, Allison TJ 6-mercaptopurine modifies cerebrospinal fluid $\mathrm{T}$ cell abnormalities in paediatric opsoclonus-myoclonus as steroid sparer. Clin Exp Immunol. 2017;190:217-25.

21. Denne C, Klienes M, Scheithauer S, Heimann G, Häusler M. Methotrexate: a new treatment in opsoclonus-myoclonus syndrome. J Pediatr Neurol. 2006;4:183-5. 